\title{
Temporal influences on the prediction of postinfarction mortality by heart rate variability: a comparison with the left ventricular ejection fraction
}

Olusola Odemuyiwa, Jan Poloniecki, Marek Malik, Thomas Farrell, Ruiping Xia, Anne Staunton, Piotr Kulakowski, David Ward, John Camm

\begin{abstract}
Objective-To examine the influence of the duration of follow up on the values of heart rate variability (HRV) and the left ventricular ejection fraction (LVEF) for predicting mortality after infarction.

Background-HRV is an index of autonomic balance that identifies patients at a high risk of arrhythmic events. The index is most depressed during the first few weeks after myocardial infarction whereas left ventricular function tends to deteriorate with time.

Hypothesis-The value of depressed HRV measured before discharge from hospital for predicting mortality after infarction should decline with time.

Methods-The HRV and the LVEF were assessed in 433 survivors of a first acute myocardial infarction: HRV $<20$ units and LVEF $<40 \%$ were taken as cut off points. Kaplan-Meier survival functions for total cardiac mortality and sudden cardiac death were calculated for the whole five year follow up period and for different intervening periods.
\end{abstract}

Results-During follow up of four weeks to five years there were $46(10 \cdot 6 \%)$ deaths and $15(3.5 \%)$ patients died suddenly. Within the whole follow up period, HRV $<20$ units and LVEF $<40 \%$ were both strongly associated with total cardiac mortality ( $<<0.0001$ ), but HRV was an independent predictor of total cardiac mortality only during the first six months of follow up. There were no deaths predicted by $H R V<20$ units after the first year of follow up whereas LVEF $<40 \%$ had a sensitivity of $43 \%$ and a positive predictive accuracy of $9 \%$ for predicting death during this period. HRV $<20$ units was better than LVEF $<\mathbf{4 0 \%}$ in predicting sudden deaths during the first year of follow up but was an independent predictor only of those sudden deaths occurring within six months of infarction.

Conclusions-The duration of follow up affects the prediction of sudden death and total cardiac mortality from HRV. Reduced HRV as measured before discharge from hospital does not seem to retain independent prognostic value after six months of follow up. These findings have potential implications for the serial evaluation of HRV and for the prevention of sudden death after myocardial infarction.

(Br Heart f 1994;71:521-527)

The balance between cardiac sympathetic and vagal efferent activity is reflected in beat by beat oscillations of the cardiac cycle. ${ }^{12}$ The magnitude of these oscillations can be assessed by measuring heart rate variability (HRV) from ambulatory electrocardiographic recordings. As sympathetic predominance predisposes to ventricular arrhythmias, whereas vagal stimulation is protective, ${ }^{3}$ the assessment of HRV provides a means of predicting mortality after myocardial infarction, ${ }^{45}$ particularly from arrhythmic events. ${ }^{67}$

The HRV is most obviously depressed during the first few weeks after myocardial infarction, ${ }^{8-10}$ whereas left ventricular function tends to deteriorate with time, particularly after extensive infarction. ${ }^{11}$ Therefore, assuming causality between sympathovagal imbalance and mortality, the predictive value of a low HRV measured early after infarction should decline with time; whereas a low LVEF before discharge from hospital should be better for predicting late mortality. The implications of this hypothesis were examined by comparing the HRV and the LVEF as predictors of mortality during different periods of follow up after a first myocardial infarction.

\section{Patients and methods} PATIENTS

The study population comprised patients aged under 70 admitted to hospital with a first acute myocardial infarction. Acute myocardial infarction was diagnosed if two of three criteria were met: (a) characteristic chest pain lasting for at least 30 minutes; (b) a sequential rise and fall in plasma concentrations of aspartate transaminase, $\beta$ hydroxybutyric dehydrogenase, or creatine kinase with a peak concentration at least twice the upper limit of the reference range of our laboratory; (c) development of new pathological $Q$ waves or persistent ST changes suggestive of non- $Q$ wave infarction. Only patients admitted directly to our hospital and who survived the first five days in hospital were considered for this prospective study. Patients $(n=126)$ with atrial fibrillation, inadequate or missing Holter recordings, a history of cardiac 
Table 1 Patient characteristics $($ total $=$ 433)

\begin{tabular}{lc}
\hline Characteristic & No (\%) \\
\hline $\begin{array}{l}\text { Men } \\
\text { Anterior }\end{array}$ & $316(73)$ \\
$\quad$ myocardial & $209(48)$ \\
infarction & \\
Q wave & $285(66)$ \\
$\begin{array}{l}\text { History of } \\
\text { hypertension }\end{array}$ & $93(21)$ \\
$\begin{array}{l}\text { Diabetes mellitus } \\
\text { History of angina }\end{array}$ & $50(12)$ \\
$\begin{array}{l}\text { Discharged on } \\
\quad \beta \text { blockers }\end{array}$ & $174(40)$ \\
Thrombolytic & $229(53)$ \\
treatment & \\
Discharged on & $248(578)$ \\
$\quad$ aspirin & \\
Killip class $>1$ & $78(18)$ \\
Killip class $>2$ & $26(6)$ \\
Revascularisation & $91(21)$ \\
LVF in hospital & $67(16)$ \\
HRV < 20 units & $34(8)$ \\
LVEF < 40 & $110(25)$ \\
LVEF < 40 or & $125(29)$ \\
HRV < 20 units & \\
LVEF < $40 \%$ and & $19(4)$ \\
HRV $<20$ units &
\end{tabular}

LVF, Left ventricular failure. surgery, or permanent pacemaker insertion were excluded from the analysis of HRV.

The following investigations were carried out before discharge from hospital: (a) Ambulatory 24 hour electrocardiographic recordings with a Reynolds Tracker two channel recorder (leads II and CM5). All recordings were made with patients taking no antiarrhythmic treatment but 75 patients were taking $\beta$ blockers during the recording. (b) A maximal exercise test with a Bruce protocol, and patients with abnormal exercise tests underwent cardiac catheterisation before discharge. The management of these patients was decided by the patient's physician and cardiologist but antiarrhythmic treatment was not routinely prescribed. The LVEF was calculated from angiograms by the Dodge formula. ${ }^{12}$ The LVEF in other patients was assessed by radionuclide angiography.

\section{MEASUREMENT OF HRV}

The 24 hour recordings were digitised off line at the analog to digital sampling rate of 128 $\mathrm{Hz}$ by a Marquette 8000 scanner. Each QRS complex was classed as normal or aberrant based on the matching pairs principle. The classification was manually checked and corrected and the data files transferred to diskettes. The HRV was calculated from the sequence of the durations of the intervals between adjacent QRS complexes of normal morphology (the normal to normal intervals). Extrasystolic beats were corrected for by linear interpolation with the adjacent beats. As described previously, the HRV index was derived by plotting a frequency distribution histogram of the normal to normal $R R$ intervals and then measuring the baseline width of the minimum square difference triangular interpolation of this histogram. ${ }^{613}$ The result is expressed in technical units. The HRV index was dichotomised at $<20$ units because we have shown that this value best distinguished patients with arrhythmic events from those without. ${ }^{6}$

\section{FOLLOW UP AND RISK STRATIFICATION}

The patients were followed up in a clinic dedicated to the care of patients with myocardial infarction with visits at three to four weeks after discharge from hospital, then at three months, and subsequently at least once a year or more often as clinically indicated. Special attention is paid to compliance with medication, the modification of risk factors, such as smoking, hyperlipidaemia, and hypertension, and these were noted at each visit. The main end points of sudden and non-sudden death were classified by a group of physicians without knowledge of the results of risk stratification. As in the cardiac arrhythmia pilot study, ${ }^{14}$ sudden cardiac death included instantaneous deaths as well as unwitnessed death that occurred within an hour of last being seen alive. The circumstances were determined by interviewing the relatives and the general practitioner. Non sudden cardiac deaths were also defined as in previous studies. ${ }^{14}$
STATISTICAL ANALYSIS

Results are expressed as mean (SD). Differences between mean values of continuous variables were examined by the Student's $t$ test, and the $\chi^{2}$ test with Yates' correction was used for examining the relation between type of infarct, Killip class, thrombolytic treatment, and cardiac mortality during follow up.

Survival data were analysed with the SAS statistical package. Kaplan-Meier survival functions for sudden cardiac death and total cardiac mortality were calculated for the whole five-year follow up period and for the following intervening periods: $0-5$ years; $0-1$ year; 0-6 months; 6 months -5 years; 6 months -1 year; and 1-5 years). The univariate associations between depressed heart rate variability (HRV $<20$ units), a low $L V E F$ (LVEF $<40 \%$ ), and total cardiac mortality and sudden cardiac death during these intervals were examined with the log rank test.

Cox's proportional hazards linear regression was used to determine whether HRV conveyed additional information for the prediction of mortality during the periods of follow up, when LVEF was available. As they are not data from investigations and hence are always available, thrombolytic treatment, $\beta$ blocker treatment, age, and sex were incorporated into all our models examining the possible further contribution of HRV. Thrombolytic treatment, $\beta$ blockade at discharge from hospital, and sex were used as dichotomous variables, whereas age and mean heart rate on Holter monitoring were allowed for in the models as continuous variables. The LVEF was first incorporated into the model and the strength of the marginal association between a depressed HRV index and survival was then inferred from the $\chi^{2}$ coefficient statistic score. A p value $<0.05$ was considered to be significant.

For ease of interpretation, and because these measures are the most important to clinical practice, the sensitivity and positive predictive accuracy of LVEF and HRV separately and in combination with each other were calculated as indicators of the potential usefulness of the predictions available.

\section{Results}

Table 1 describes the clinical characteristics of the 433 patients aged under 70 with a first myocardial infarction who were enrolled in the study. The mean (SD) age of the patients was $56.7(12)$ and $316(73 \%)$ were men. The LVEF ranged from $10 \%$ to $85 \%$ (mean (SD) $47 \%(14 \%)$ ) and the HRV from 4 to 126 units (mean (SD) 50 (22) units). The HRV correlated weakly with LVEF $(r=0.3$, $\mathrm{p}<0.001)$ and moderately with mean heart rate on Holter monitoring $(r=0.6, \mathrm{p}<$ $0.001)$ and was higher after non- $Q$ wave than after $Q$ wave infarction (53 (21) $v 48$ (22) units, $\mathrm{p}=0.01$ ). Table 2 shows the relation between Killip class in hospital and the HRV and LVEF before discharge

During a follow up period from four weeks to five years there were $46(10 \cdot 6 \%)$ deaths 
Table 3 Ratio of sudden deaths ( $S$ death) to total cardiac mortality (TCM) during different periods of follow up

\begin{tabular}{ll}
\hline Period (yr) & $\begin{array}{l}S \text { death/TCM } \\
(\%)\end{array}$ \\
\hline $0-5$ & $15 / 46(33)$ \\
$0-1$ & $11 / 25(44)$ \\
$0-0.5$ & $9 / 18(50)$ \\
$0.5-5$ & $6 / 28(21)$ \\
$1-5$ & $4 / 21(19)$ \\
$0.5-1$ & $2 / 7(29)$ \\
\hline
\end{tabular}

Figure 1 Survival curves showing the association without adjustment for other variables between $H R V<20$ units and total cardiac mortality (TCM) during different follow up intervals $(y r):(A)$ 0-5; (B) $0-1 ;(C) 0-0.5 ;(D)$ $0.5-5 ;(E) 0.5-1 ;$ and $(F)$ $1-5$. The $p$ values in parentheses are after adjustment for other clinical variables by Cox's proportional hazards linear regression analysis. and $15(3.5 \%)$ patients died suddenly. Table 3 shows the proportion of sudden deaths to total cardiac mortality during the different follow up periods.

UNIVARIATE AND MULTIVARIATE ASSOCIATION BETWEEN LVEF, HRV, AND TOTAL CARDIAC MORTALITY DURING DIFFERENT PERIODS OF FOLLOW UP

Table 4 shows the relation between clinical variables and total cardiac mortality during follow up. Figure 1 represents the association between $\mathrm{HRV}<20$ units and total cardiac mortality during various periods of follow up. Within the whole follow up period, HRV $<20$ units and LVEF $<40 \%$ were each strongly associated with total cardiac mortality $(p<$
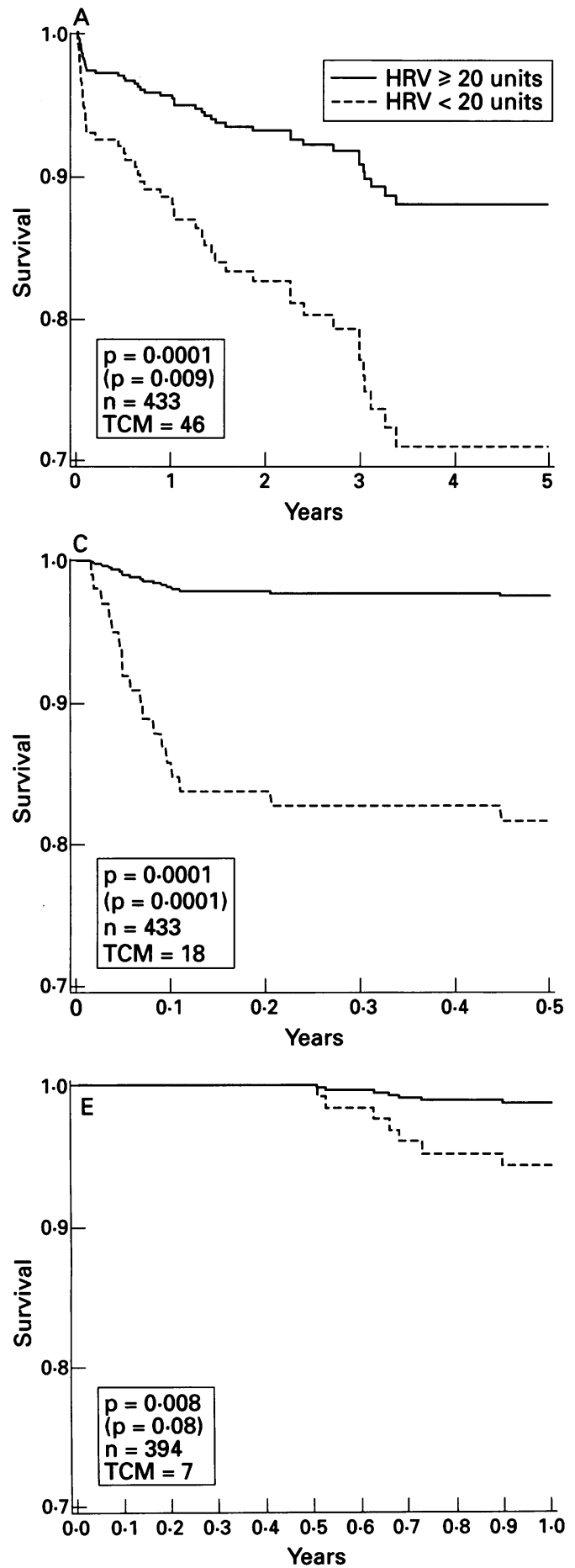

0.0001 ), but HRV was an independent predictor of total cardiac mortality only during the first six months of follow up. That is, there is a significant difference in mortality between patients with HRV $<20$ units and those with $H R V \geqslant 20$ units only when the first six months of follow up are included in the analysis whether or not adjustment is made for LVEF and other variables. The ratio of sudden deaths to total cardiac mortality was $50 \%$ during this period.

PREDICTIVE CHARACTERISTICS OF LVEF AND HRV FOR TOTAL CARDIAC MORTALITY DURING DIFFERENT PERIODS OF FOLLOW UP

Of the 34 patients with HRV $<20$ units, 10 died during the first year, but none of the
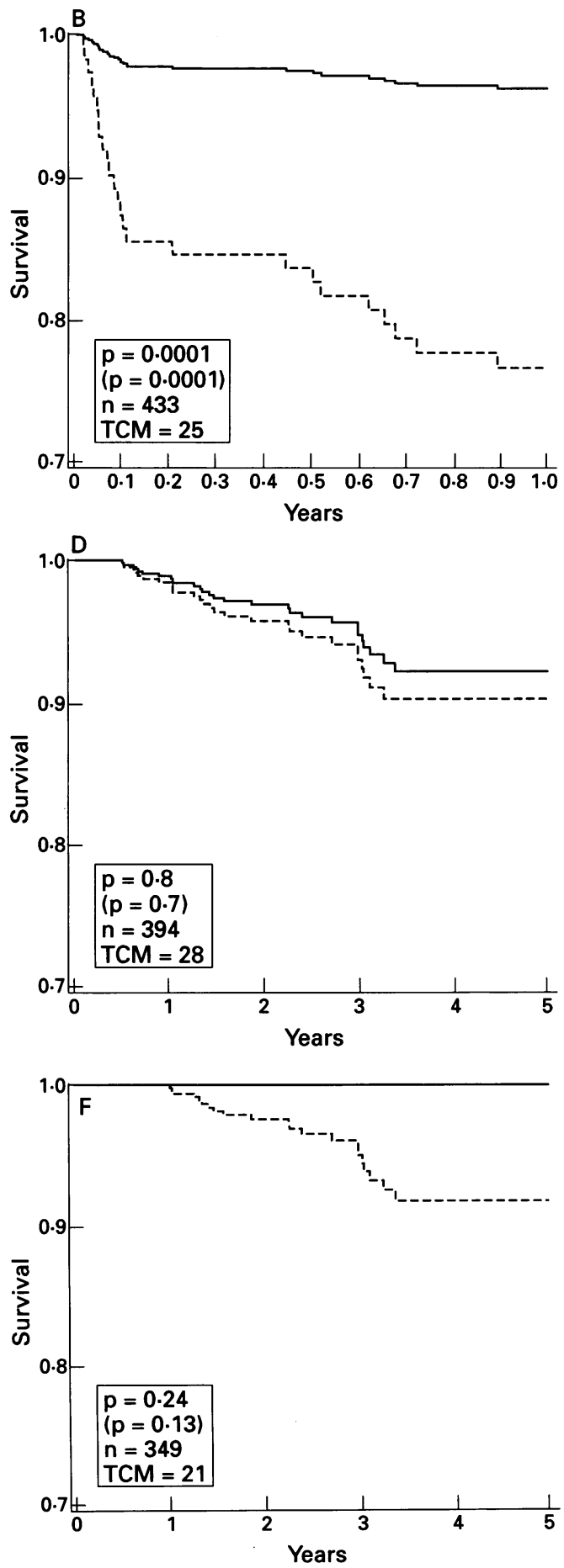
Figure 2 Survival curves showing the association without adjustment for other variables between $H R V<20$ units and sudden death (S Death) after adjusting for the $L V E F$ and other variables (see text), during different follow up intervals $(y r)$ : (A) $0-5 ;(B) 0-1 ;$ (C) (A) $0-5 ;(B) 0-1 ;(C)$
$0-0.5 ;(D) 0.5-5 ;(E)$ $0.5-1$; and (F) $1-5$. As in fig 1 the $p$ values in parentheses are calculated with proportional hazards analysis. remaining 24 patients died during subsequent follow up. Table 5 shows that the HRV $<20$ units therefore had a sensitivity of $40 \%$ and a positive predictive accuracy of $29 \%$ during the first year. An LVEF $<40 \%$ had a sensitivity of $48 \%$ and positive predictive accuracy of $11 \%$ during the first year and the presence of either LVEF $<40 \%$ or $\mathrm{HRV}<20$ units increased sensitivity to $64 \%$. After the first year LVEF $<40 \%$ had a sensitivity of $43 \%$ and a positive predictive accuracy of $9 \%$ for predicting total cardiac mortality, but there were no deaths predicted by $\mathrm{HRV}<20$ units during this period.
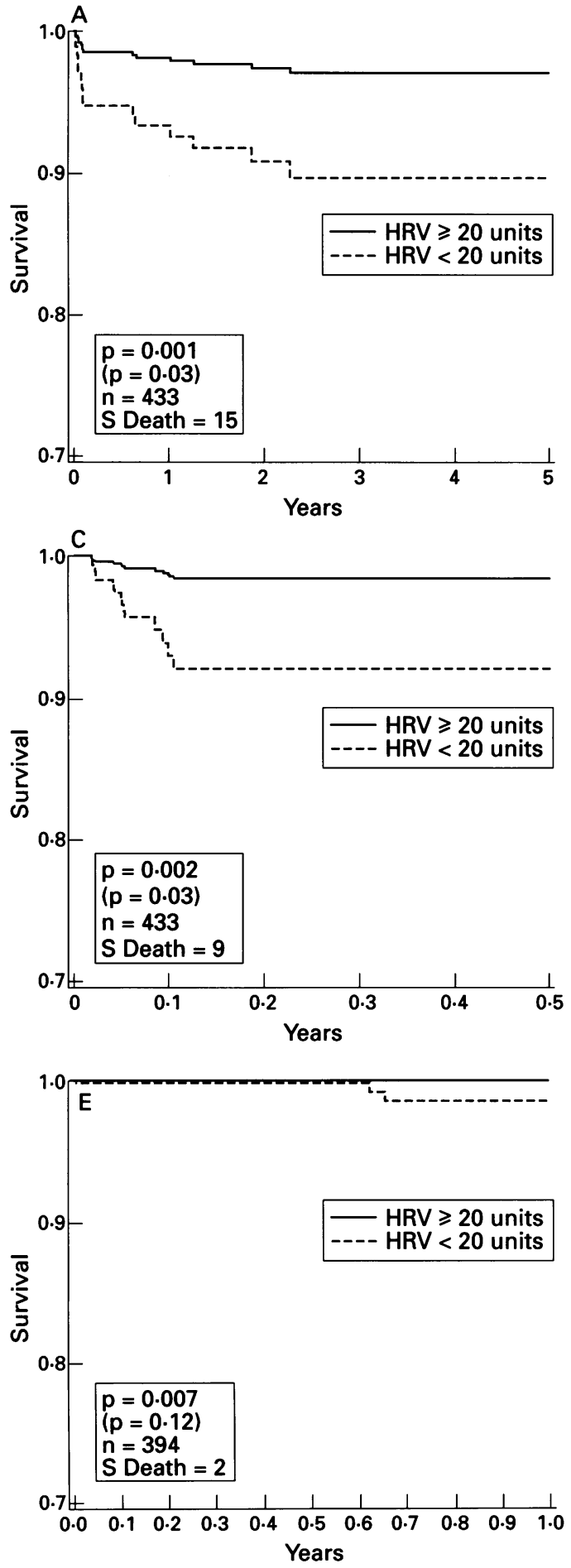

UNIVARIATE AND MULTIVARIATE ASSOCIATION BETWEEN LVEF, HRV, AND SUDDEN DEATH DURING DIFFERENT PERIODS OF FOLLOW UP Table 4 shows the relation between clinical variables and sudden deaths during follow up. Figure 2 represents the association between HRV $<20$ units and sudden cardiac death during various periods of follow up. Within the whole follow up period, $\mathrm{HRV}<20$ units seemed to be more closely associated with sudden cardiac death than was the LVEF < $40 \%$. This association was particularly strong during the first six months after infarction. Compared with LVEF $<40 \%$, HRV $<20$
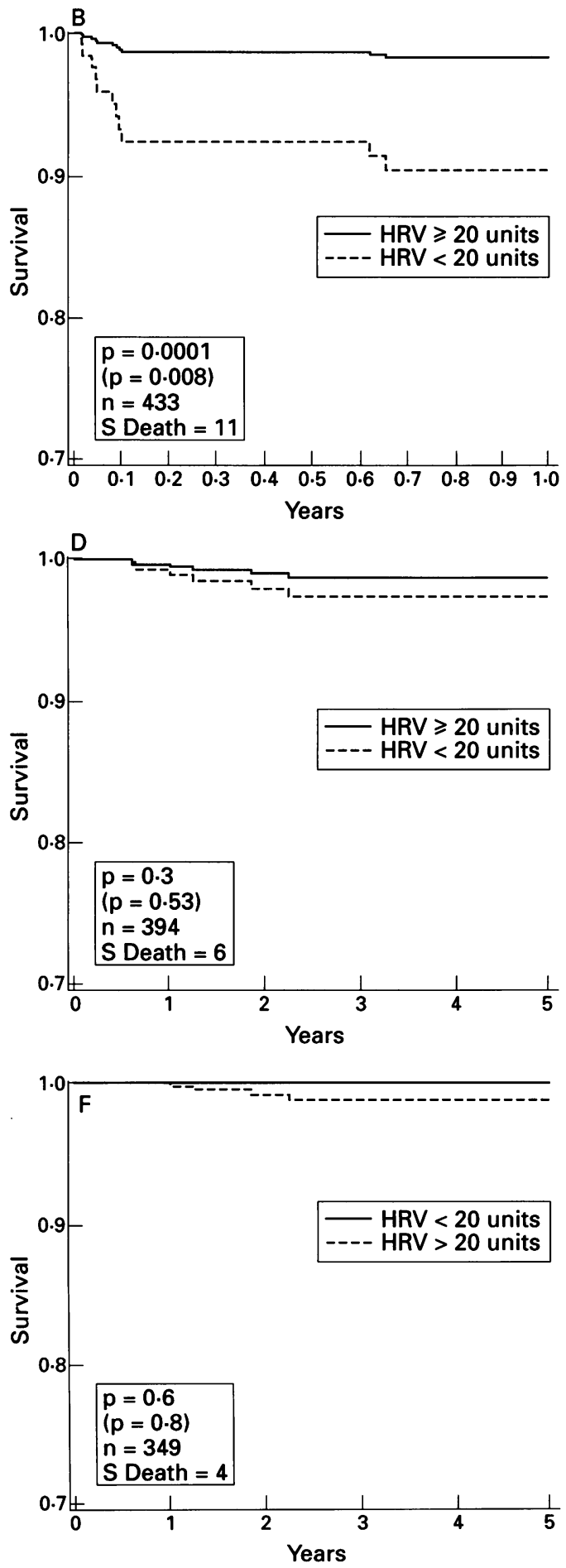
Table 4 Relation between clinical variables, HRV, LVEF, and total cardiac mortality (TCM) and sudden cardiac death $(S$ death) during follow up

\begin{tabular}{|c|c|c|c|c|c|c|c|c|}
\hline & $\begin{array}{l}\text { Yes } \\
(n)\end{array}$ & $\begin{array}{l}T C M \\
(n(\%))\end{array}$ & $\begin{array}{l}S \text { death } \\
(n(\%))\end{array}$ & $\begin{array}{l}\text { No } \\
(n)\end{array}$ & $\begin{array}{l}T C M \\
(n(\%))\end{array}$ & $\begin{array}{l}S \text { death } \\
(n(\%))\end{array}$ & $\begin{array}{l}p \text { Value } \\
(\text { TCM })\end{array}$ & $\begin{array}{l}p \text { Value } \\
\text { (S death) }\end{array}$ \\
\hline $\begin{array}{l}\text { HRV }<20 \text { units } \\
\text { LVEF }<40 \% \\
\text { Killip }>1 \\
\text { Killip }>2 \\
\text { Mean heart rate }>80 \\
\text { Thrombolytic treatment } \\
\text { Hypertension } \\
\text { Past angina } \\
\text { Diabetes } \\
Q \text { wave myocardial infarction } \\
\text { Anterior myocardial infarction }\end{array}$ & $\begin{array}{r}34 \\
110 \\
78 \\
26 \\
128 \\
229 \\
93 \\
57 \\
50 \\
285 \\
209\end{array}$ & $\begin{array}{l}10(29) \\
21(19) \\
21(27) \\
10(39) \\
25(20) \\
19(8) \\
13(14) \\
7(12) \\
7(14) \\
34(12) \\
22(11)\end{array}$ & $\begin{aligned} 4(12) \\
7(6) \\
6(8) \\
3(12) \\
10(8) \\
7(3) \\
3(3) \\
3(5) \\
2(4) \\
10(3 \cdot 5) \\
7(3)\end{aligned}$ & $\begin{array}{l}399 \\
323 \\
355 \\
407 \\
305 \\
204 \\
340 \\
376 \\
383 \\
148 \\
224\end{array}$ & $\begin{array}{l}36(9) \\
25(7) \\
25(7) \\
36(9) \\
21(7) \\
27(13) \\
33(10) \\
39(10) \\
39(10) \\
12(8) \\
24(11)\end{array}$ & $\begin{aligned} & 11(3) \\
& 25(2 \cdot 5) \\
& 9(2 \cdot 5) \\
& 12(3) \\
& 5(1 \cdot 6) \\
& 8(4) \\
& 12(3 \cdot 5) \\
& 12(3) \\
& 14(4) \\
& 5(3 \cdot 4) \\
& 8(4 \cdot 5)\end{aligned}$ & $\begin{array}{l}<0.001 \\
<0.001 \\
<0.001 \\
<0.001 \\
<0.001 \\
\text { NS } \\
\text { NS } \\
\text { NS } \\
\text { NS } \\
\text { NS } \\
\text { NS }\end{array}$ & $\begin{array}{l}<0.05 \\
<0.05 \\
\text { NS } \\
\text { NS } \\
<0.01 \\
\text { NS } \\
\text { NS } \\
\text { NS } \\
\text { NS } \\
\text { NS } \\
\text { NS }\end{array}$ \\
\hline
\end{tabular}

Table 5 Sensitivity (S) and positive predictive accuracy (PPA) of HRV $<20$ units and LVEF $<40 \%$ for sudden death ( $S$ death) and total cardiac mortality (TCM) during different follow up periods

\begin{tabular}{|c|c|c|c|c|c|c|c|c|c|c|c|c|c|c|c|c|}
\hline \multirow{3}{*}{$\begin{array}{l}\text { Follow } \\
\text { up period } \\
\text { (yr) }\end{array}$} & \multicolumn{8}{|c|}{$S$ death } & \multicolumn{8}{|c|}{$T C M$} \\
\hline & \multicolumn{2}{|c|}{$H R V$} & \multicolumn{2}{|c|}{$L V E F$} & \multicolumn{2}{|c|}{$\begin{array}{l}H R V \text { and } \\
L V E F\end{array}$} & \multicolumn{2}{|c|}{$\begin{array}{l}\text { HRV or } \\
L V E F\end{array}$} & \multicolumn{2}{|c|}{$H R V$} & \multicolumn{2}{|c|}{$L V E F$} & \multicolumn{2}{|c|}{$\begin{array}{l}H R V \text { and } \\
L V E F\end{array}$} & \multicolumn{2}{|c|}{$\begin{array}{l}H R V \text { or } \\
L V E F\end{array}$} \\
\hline & $S$ & $P P A$ & $S$ & $P P A$ & $S$ & $P P A$ & $S$ & $P P A$ & $S$ & $P P A$ & $S$ & $P P A$ & $S$ & $P P A$ & $S$ & $P P A$ \\
\hline $\begin{array}{l}0-5 \\
0-1 \\
0-0 \cdot 5 \\
0 \cdot 5-5 \\
0 \cdot 5-1 \\
1-5\end{array}$ & $\begin{array}{r}27 \\
36 \\
33 \\
17 \\
50 \\
0\end{array}$ & $\begin{array}{r}12 \\
12 \\
9 \\
5 \\
4 \\
0\end{array}$ & $\begin{array}{r}47 \\
45 \\
33 \\
67 \\
100 \\
50\end{array}$ & $\begin{array}{l}6 \\
5 \\
3 \\
4 \\
2 \\
2\end{array}$ & $\begin{array}{r}20 \\
27 \\
22 \\
4 \\
17 \\
0\end{array}$ & $\begin{array}{r}16 \\
16 \\
11 \\
7 \\
17 \\
0\end{array}$ & $\begin{array}{r}53 \\
55 \\
44 \\
67 \\
100 \\
50\end{array}$ & $\begin{array}{l}6 \\
5 \\
3 \\
4 \\
2 \\
2\end{array}$ & $\begin{array}{r}22 \\
40 \\
42 \\
8 \\
33 \\
0\end{array}$ & $\begin{array}{r}29 \\
29 \\
24 \\
10 \\
8 \\
0\end{array}$ & $\begin{array}{l}46 \\
48 \\
42 \\
52 \\
67 \\
43\end{array}$ & $\begin{array}{r}19 \\
11 \\
7 \\
13 \\
4 \\
9\end{array}$ & $\begin{array}{l}13 \\
24 \\
26 \\
17 \\
50 \\
25\end{array}$ & $\begin{array}{r}32 \\
32 \\
26 \\
7 \\
7 \\
8\end{array}$ & $\begin{array}{l}54 \\
64 \\
58 \\
56 \\
33 \\
43\end{array}$ & $\begin{array}{r}20 \\
13 \\
9 \\
12 \\
2 \\
8\end{array}$ \\
\hline
\end{tabular}

units was less predictive of sudden death after the first six months of follow up and HRV < 20 units was an independent predictor of sudden death only during the first six months after infarction.

\section{PREDICTIVE CHARACTERISTICS OF LVEF AND HRV FOR SUDDEN CARDIAC DEATH DURING DIFFERENT PERIODS OF FOLLOW UP}

Table 5 shows that of the 34 patients with HRV $<20$ units, four died suddenly during the first year, giving a sensitivity of $36 \%$ and a positive predictive accuracy of $12 \%$ : but none of the remaining 30 patients died during subsequent follow up. The LVEF $<40 \%$ had a sensitivity of $45 \%$, but a positive predictive accuracy of only $5 \%$ for predicting sudden death during the first year. The LVEF and HRV identify different patients, as shown by the increase in sensitivity to $55 \%$ when patients with either LVEF $<40 \%$ or HRV $<$ 20 units are considered. An LVEF $<40 \%$ had a sensitivity of $50 \%$ for predicting sudden death between one and five years after infarction.

\section{EFFECTS OF TREATMENT}

The use of thrombolytic treatment did not affect HRV (50 (21) v 49 (23) units) or LVEF $(47 \%(13 \%) v 45 \%(14 \%))$. There was a trend towards a lower total cardiac mortality $(8 \% v 13 \%)$ in patients who received thrombolytic treatment, but this difference did not reach significance (table 4). Thrombolytic treatment did not seem to influence the sudden death rates (table 4).

The HRV (57 (20) v 45 (21) units, p< 0.0001 ), LVEF (49\% (12\%) v 45\% (15\%)) were higher and the mean heart rate on Holter monitoring was lower (68 (11) $v 78$ (14) beats/min) in patients discharged from hospital on $\beta$ blockers. Patients with pulmonary congestion or left ventricular failure in hospital were generally excluded from $\beta$ blocker treatment on discharge: only eight $(10 \%)$ of the 78 patients in Killip class $>1$ and two $(8 \%)$ of the 26 patients in Killip class $>2$ were discharged on $\beta$ blockers. None of the 16 patients with Killip class $>1$ and who had HRV $<20$ were treated with $\beta$ blockers but five $(19 \%)$ of these 16 patients were discharged on angiotensin converting enzyme inhibitors. Of the 128 patients with mean heart rate $<80$ beats/min on Holter monitoring, $64(50 \%)$ were discharged on $\beta$ blockers, compared with $110(36 \%)$ of the 305 patients with a higher mean heart rate $(p<0.01)$. When $\beta$ blocker treatment was entered into the multivariate model the relation between HRV and cardiac mortality was unaffected. There was no direct relation between patient compliance with medication during follow up and the main variables examined in the study.

\section{Discussion}

The HRV reflects changes in the balance between cardiac sympathetic and vagal efferent activity, ${ }^{12}$ and its assessment has provided a means of identifying high risk patients after myocardial infarction. ${ }^{45}$ Our study shows that the HRV index before discharge from hospital is more reliable than the LVEF only for predicting those sudden deaths that occur early after infarction.

Our findings may be explained by a spontaneous improvement in HRV itself. Myocardial infarction is associated with a transient reduction in parasympathetic activity ${ }^{1516}$ and HRV shows a similar trend..$^{8-10}$ This change in sympathovagal balance has been 
ascribed to activation or interruption of cardiac autonomic reflexes by direct ischaemia or mechanical distortion or disruption of cardiac afferent nerve receptors and to sensory nerve endings lying in an ischaemic milieu. ${ }^{17}$ The severity and duration of these changes in autonomic function and whether they are mainly due to reflex activation or interruption may depend on the extent and site of myocardial damage and whether infarction is transmural or non-transmural. ${ }^{17}$ These changes coincide with and may be responsible for the high mortality early after myocardial infarction. It has been suggested that the subsequent improvement in sympathovagal balance and HRV and hence in mortality may be due to reversal of ischaemia, the washing out of ischaemic metabolites, receptor necrosis, or to the adaptation of the receptors to continuing mechanical and chemical stimuli. ${ }^{18} 19$

Another potential explanation for our findings could have arisen if patients with low HRV before discharge had been selected for treatment that had then resulted in early mortality. This was not the case as drug treatment, including $\beta$ blocker, was uncontrolled and clinical management was decided by the referring physician and cardiologist on the basis of the clinical findings, the exercise test, and angiography, but without the results of Holter monitoring. Nevertheless, that the LVEF and HRV were higher and the Killip class lower in patients discharged from hospital on $\beta$ blockers does indicate patient selection. For instance, none of the 16 patients with Killip class $>2$ in whom HRV $<20$ units were discharged on $\beta$ blockers and only two of these patients were discharged on angiotensin converting enzyme inhibitors. The value of $\beta$ blocker treatment or other means of autonomic manipulation early after infarction in this subgroup of patients needs further study.

We found that a low HRV index identified some patients who died but who did not have a low LVEF. One explanation is that myocardial infarction need not be extensive to result either in denervation supersensitivity, which makes the heart more susceptible to arrhythmias, ${ }^{20}$ or in the selective destruction of inhibitory vagal afferents, ${ }^{21-23}$ which would lead to increased efferent sympathetic activity. In other patients a normal LVEF may be maintained by reflex, but potentially deleterious increases in sympathetic drive. Sympathetic predominance in the early period after infarction may also be due to diuretic treatment, sodium restriction in hospital, ${ }^{24}$ and anxiety.

The association between a low LVEF before discharge and late sudden deaths may be due to a gradual deterioration in left ventricular function consequent on infarct expansion and ventricular remodelling, ${ }^{25}$ and may well be associated with a fall or an attenuation in the expected rise in HRV in the weeks after myocardial infarction. This needs to be confirmed. Patients with LVEF $<40 \%$ were less likely to die suddenly than to die of circulatory failure, whereas patients with HRV $<20$ units were more closely associated with sudden death than with all cause mortality, perhaps because the dichotomy point for HRV was designed for predicting arrhythmic events. ${ }^{6}$ Alternatively, HRV may not become as obviously depressed in patients dying of circulatory failure as it does in those at a high risk of dying suddenly. Another possibility is that HRV may only become noticeably depressed in patients subsequently dying of circulatory failure only after heart failure is clinically apparent.

\section{STUDY LIMITATIONS}

A limitation of our study was that serial evaluation of HRV was not undertaken. On the basis of previous studies, however, we think that our assumption that HRV tends to rise after myocardial infarction is correct. Even had serial evaluation of HRV shown that HRV did not change with time this would not have altered our findings with respect to the prognostic value of the HRV before discharge from hospital. Another drawback of our study is the small number of events during each follow up period: but by selecting several overlapping intervals we have shown that the duration of follow up has an important influence on the prediction of sudden death and total cardiac mortality.

\section{CLINICAL IMPLICATIONS}

Reduced HRV as measured before discharge from hospital, unlike reduced LVEF, does not seem to have continued significance if the patient survives for six months or longer. The findings provide additional evidence for a causal relation between autonomic dysfunction and sudden death in patients after infarction. ${ }^{26}$ The relatively small group of patients with low HRV ( $8 \%$ in our study) may benefit from attention to likely reversible causes of autonomic dysfunction, or provide the basis for prospective studies into the value of prophylactic pharmacological manipulation of autonomic tone. ${ }^{27}$ The study also shows that about $33 \%$ of patients at high risk of sudden death early after infarction may be missed if risk stratification is based solely on the LVEF. Repeat assessment of HRV, however, or other measures of sympathovagal activity after discharge may improve the prediction of late sudden death, particularly in patients with poor left ventricular function. Studies of the relation between the evolution of cardiac function and prognosis after infarction may establish the best time to repeat the investigations. The study also has implications for the planning of prospective double blind studies into the prevention of sudden death after myocardial infarction based on HRV. Such studies should be based on a recent assessment of HRV. The recently published study of captopril in patients with poor left ventricular function after infarction showed that there was no difference in mortality between treated and untreated patients during the first six months of follow up. ${ }^{28}$ The assessment of HRV before discharge may provide a basis for studies aimed at reducing cardiac mortality during this period. 
1 Ewing DJ. Cardiovascular reflexes and autonomic neuropathy. Clin Sci Mol Med 1978;55:321-7.

2 Katona PG, Jih F. Respiratory sinus arrhythmia: noninvasive measure of parasympathetic cardiac control. $\mathcal{F}$ Appl Physiol 1975;39:801-5.

3 Myers RW, Pearlman AS, Hyman RM, et al. Beneficial effects of vagal stimulation and bradycardia during experimental acute myocardial infarction. Circulation 1974;49:943-7.

4 Wolf MM, Varigos GA, Hunt D, Sloman JG. Sinus arrhythmia in acute myocardial infarction. Med $\mathcal{f}$ Aust

5 Kleiger RE, Miller JP, Bigger JT, Moss AJ, and the MPIRG. Decreased heart rate variability and its association with increased mortality after acute myocardial infarction. Am F Cardiol 1987;59:256-62.

6 Farrell TG, Bashir Y, Cripps T, Malik M, Poloniecki J, Bennett D, Ward DE, Camm AJ. Risk stratification for arrhythmic events in postinfarction patients based on heart rate variability, ambulatory electrocardiographic variables and the signal-averaged electrocardiogram. f Am Coll Cardiol 1991;18:687-97.

7 Odemuyiwa O, Malik M, Farrell TG, Bashir Y, Poloniecki J, Camm AJ. A comparison of the predictive characteristics of heart rate variability and left ventricular ejection fraction for all-cause mortality, arrhythmic events and sudden death after acute myocardial infarction. $A m \mathcal{F}$ Cardiol 1991;64:434-9.

8 Bigger TJ, Fleiss JL, Rolnitzky LM, Steinman RC, Schneider WJ. Time course of recovery of heart period variability after myocardial infarction. $\mathscr{f} \mathrm{Am}$ Coll Cardiol 1991;18:1643-9.

9 Lombardi F, Sandrone G, Pernpruner S, Sala R, Garimoldi M, Cerutti S, et al. Heart rate variability as an index of sympatho-vagal interaction in patients after myocardial infarction. Am f Cardiol 1987;60:1239-45.

10 Casolo GC, Stroder P, Signorini C, Calzolari F, Zucchini $\mathbf{M}$, Balli E, et al. Heart rate variability during the acute phase of myocardial infarction. Circulation 1992;85: 2073-9.

11 Pfeffer MA, Braunwald E. Ventricular remodelling after myocardial infarction: experimental observations and clinical implications. Circulation 1990;81:1161-72.

12 Sandler $H$, Dodge $H$. The use of single plane angiocardiograms for the calculation of left ventricular volume in grams for the calculation of left
man. Am Heart $\mathcal{1} 1968 ; 75: 325-34$.

13 Cripps T, Malik M, Farrell T, Camm AJ, Ward DE. Clinical application of a new method for quantification of heart rate variability in acute myocardial infarction patients: performance in comparison with other prognostic indicators. Br Heart $\mathcal{F}$ 1991;65:14-9.

14 Greene $\mathrm{H}$, Richardson D, Barker A, et al and the Cardiac Arrhythmia Pilot Study Investigators. Classification of deaths after myocardial infarction as arrhythmic or nonarrhythmic. Am f Cardiol 1989;63:1-6.
15 Ryan C, Hollenberg M, Harvey DB, Gwynn R. Impaired parasympathetic responses in patients after myocardial infarction. $A m \mathcal{F}$ Cardiol 1976;37:1013-8.

16 Rotschild M, Rotschild A, Pfeifer M. Temporary decrease in cardiac parasympathetic tone after acut

17 Zipes DP. Influence of myocardial ischaemia and infarction on autonomic innervation of heart. Circulation 1990; 82:1095-105.

18 Barber MJ, Mueller TM, Henry DD, Fetten SI, Zipes DP Transmural myocardial infarction in the dog produces
sympathectomy in noninfarcted myocardium. Circulation sympathectomy in

19 Bishop VS, Malliani A, Thoren PN. Cardiac mechanoceptors. In: Shepherd JI, Abboud FM. Handbook of physiology. The cardiovascular system. Vol III, part 2. Bethesd MD: American Physiological Society, 1983:497-555.

20 Minardo JD, Tuli MM, Mock BH, Weiner RE, Pride HP, Wellman HN, Zipes DP. Scintigraphic and electrophysiologic evidence of canine myocardial sympathetic denervation and reinnervation produced by myocardial infarction or phenol application. Circulation 1988;78: 1008-19.

21 Lombardi F, Casalone C, Bella PD, Malfatto G, Pagani M, Malliani A. Global versus regional myocardial ischaemia: differences in cardiovascular and sympathetic responses in cats. Cardiovasc Res 1984;18:14-23.

22 Thoren PN. Activation of left ventricular receptors with non-medullated vagal afferent fibres during occlusion of a
coronary artery in the cat. $A m \mathcal{F}$ Cardiol 1976;37: coronary

23 Malliani A, Recordati G, Schwartz PJ. Nervous activity of afferent cardiac sympathetic fibres with atrial and ventricular endings. $\mathcal{F}$ Physiol 1973;229:457-69.

24 Hull SS Jr, Adamson PB, Vanoli E, Reynolds CM. Dietary sodium alters heart rate response to acute myocardial ischaemia in conscious dogs after myocardial infarction [abstract]. Eur Heart $\mathcal{F}$ 1991;12:217.

25 McKay RG, Pfeffer MA, Pasternak RC, et al. Left ventricular remodelling after myocardial infarction-corollary to infarct expansion. Circulation 1986;74:693-702.

26 Schwartz PJ, La Rovere MT, Vanoli E. Autonomic nervous system and sudden cardiac death. Experimental basis and clinical observations for post-myocardial infarction risk stratification. Circulation 1992;85(suppl 1):1-77-91.

27 Casadei B, Pipilis A, Sessa F, Conway J, Sleight P. Low doses of scopolamine increase cardiac vagal tone in the acute phase of myocardial infarction. Circulation 1993, 88:353

28 Pfeffer M, Braunwald E, Moye L, et al on behalf of the SAVE investigators. Effect of captopril on mortality and morbidity in patients with left ventricular dysfunction after myocardial infarction. $N$ Engl $f$ Med 1992;327: 669-77. 